\title{
O valor da mercadoria no primeiro capítulo da parte primeira do Capital de Karl Marx
}

\author{
The value of the merchandise in the first chapter of the first part of the \\ Capital of Karl Marx
}

\author{
DIEGO VINÍCIUS BRITO DOS SANTOS \\ GEIZA VENÍCIA DOS SANTOS ${ }^{2}$
}

\begin{abstract}
Resumo: O presente texto contém a pretensão de evidenciar a questão sobre a Mercadoria, posta no primeiro capítulo da parte primeira do Capital. Essa questão é importante, se considerarmos que se trata do primeiro ponto posto pelo Marx em sua obra. Desta forma, presume-se que tal temática constitui um dos mais importantes fundamentos para a elaboração da crítica a economia política feita por Marx no decorrer da obra. Assim, ao tratar-se dessas questões fundamentais, o entendimento destas pode acabar por se tornar o pressuposto para entender a essência do Capital. Por essa razão, pretende-se, através de uma leitura analítica e hermenêutica, compreender o que Marx coloca sobre o valor da Mercadoria, e com qual aspecto este valor pode apresentar-se na Mercadoria.
\end{abstract}

Palavras-chave: Mercadoria. O Capital. Valor.

Abstract: The present text contains the pretense of evidence to the question on the Merchandise, put in the first chapter of the first part of the Capital. This issue is important, if we consider that it is the first point by the Marx in its work. In this way, presumbled that such thematic is one of the most important grounds for the elaboration of the critical crop of Marx's political economy in the course of the work. Thus, when dealing with these fundamental questions of the work, the understanding of these can end up becoming the assumption to understand the essence of the Capital. For this reason, it is intended, through an analytical and hermetic reading, to understand what Marx puts on the value of the Merchandise, and with which aspect is this value ma be present in the Merchandise.

Keywords: Merchandise. The Capital. Value.

\section{Introdução}

O presente texto irá percorrer todos os pontos do primeiro capítulo na primeira parte do Capital, afim de compreender a questão acerca da Mercadoria, sobretudo, do valor da mercadoria, sendo este, manifestado em tipos de valores, a saber: valor-de-uso, valor-de-troca e valor. Ao passo que estes tipos de valores forem sendo evidenciados e caracterizados, através da leitura analítica e hermenêutica, espera-se poder perceber quais destes tipos de valores é inerente na mercadoria, através de suas propriedades naturais, e quais destes, é, através de relações sociais, corporalizada na mercadoria.

\footnotetext{
${ }^{1}$ Mestrando Filosofia no Programa de Pós-Graduação em Filsoofia (PPGFIL) pela Universidade Federal do Rio Grande do Norte (UFRN). E-mail: diego_svt@hotmail.com.br

${ }^{2}$ Graduanda do Curso de Licenciatura Plena em Filosofia do Departamento de Filosofia da Universidade Estadual do Rio Grande do Norte (UERN). E-mail: geiza_venicia@hotmail.com
} 
Nossa análise, partirá dos dois fatores da mercadoria, sendo estes: valor-de-uso e valor, evidenciando como estes se manifestam na mercadoria. Sobre o aspecto do valor, iremos dedicar um tópico, assim como fez o Marx, para compreendermos as quatros formas do valor, sendo estas: I) a forma simples, singular ou fortuita do valor; II) forma total ou extensiva do valor; III) forma geral do valor; e a IV) forma dinheiro do valor. Assim, a partir da análise da forma simples do valor, tentaremos chegar a compreensão de como esta, se desenvolve até chegar a forma dinheiro.

Ainda será tratado aqui a questão sobre o valor-de-troca, embora a questão sobre o processo de troca seja melhor trabalhada, por Marx, no segunda capítulo. Contudo, tentaremos compreender o que Marx antecipa sobre o valor-de-troca já no primeiro capítulo, onde, pelo que parece, Marx começa a preparação do terreno sobre o assunto, para posteriormente, tratá-lo de forma mais profunda. Para entendermos esse valor-de-troca, adentraremos a questão do fetichismo da mercadoria, sendo, neste ponto, o momento onde Marx começa a tratar, de forma mais vivida, a relação entre valor-de-uso e valor-de-troca, para na sequencia deste ponto, entrar, propriamente, na questão do processo de troca. Por fim, espera-se entender a importância que emana deste capítulo, em partícula, sobre a discussão acerca da questão do valor, para as discussões que irão se fazer presentes no decorrer do Capital.

\section{Os dois fatores da mercadoria: valor de uso e valor (substância e quantidade do valor)}

Marx inicia o capítulo primeiro a partir da discussão acerca da Mercadoria, apontando no primeiro item o duplo aspecto fatorial da Mercadoria, sendo estes: valor-de-uso e valor - nas entrelinhas: substância e quantidade de valor. Supondo-se que um indivíduo com alguma formação na área de economia, inicie a leitura do Capital, em algum momento, na leitura, certamente este questionar-se-á respeito da ocultação que deve/pode existir na intenção de Marx em iniciar o desenvolvimento escrito, de sua obra, a partir de tal colocação, - qual pertinência Marx encontra na questão acerca da Mercadoria? - aponto de iniciar uma de suas mais importantes obras com tal apreciação temática? Existe na mercadoria algo de importância ou algo trivial para chegar-se ao entendimento do processo de produção do capital? Sendo este, exatamente, o subtítulo do primeiro livro do Capital, e, por sua vez, a questão ancora que deve proporcionar o norteamento central em uma apreciação literária do primeiro volume da obra, e, haja vista que, todos os pontos a serem desenvolvidos por Marx, em seu escrito, devem ter a intenção inicial de chegar-se a apreciação argumentativa que comine no sentido e na concepção de Marx sobre tal questão tão enfática na produção literária marxista.

Marx inicia o escrito oferecendo uma colocação que ilumina nossa indagação inicial, sobre o algo de importante velado na questão acerca da Mercadoria, diz 
Marx, "A riqueza das sociedades onde rege a produção capitalista configura-se em “imensa acumulação de mercadorias”' (MARX, Karl. 1996, p. 41, grifo do autor). Assim, podemos perceber nitidamente que Marx percebeu que na mercadoria está contido o fator para o advento da riqueza, sendo a questão quantitativa de mercadoria - acumulação quantitativa de mercadoria -, o pressuposto para a produção de riqueza, e, consequentemente, para a produção do capital, por essa razão, diz Marx, "nossa investigação começa com a análise da mercadoria" (MARX, Karl. 1996, p. 41).

Sendo a Mercadoria o fator para a produção de riqueza, e, se isto já estiver devidamente clarificado suficientemente, resta saber, por ventura, o que é essa Mercadoria, sendo, precisamente, essa tarefa que o Marx irá ocupar-se no seguinte de seu texto, expõe ele, "mercadoria é, antes de mais nada, um objeto externo, uma coisa que, por sua propriedade, satisfaz necessidades humanas" (MARX, Karl. 1996, p. 41). Elaborar a pressuposição que algo possa atender, suficientemente, necessidades humanas, pressupõe afirmar que esse algo possuí, a partir de suas propriedades inerentes, certa utilidade de uso. Para o Marx, a "utilidade de uma coisa faz dela um valor-de-uso" (MARX, Karl. 1996, p. 42).

Aqui, Marx põe lado-a-lado "utilidade" e "valor-de-uso", dois conceitos com demasiada importância, e que, por isso, devem ser tratados com certa cautela para não os-confundir com o sentido que Marx apresentará posterior - valor. Ao passo que um objeto possua uma utilidade - sempre a partir da inerência de suas propriedades -, este passa a possuir um valor-de-uso, assim, o valor-de-uso é proporcionado na relação objeto-utilidade-necessidade, tendo em vista que, assim como postulado anteriormente, ao passo que algo possuí uma utilidade, este passa a possuir o vigor de satisfazer certa necessidade humana. Ainda sobre o valor-de-uso é importante expor dois fatores a mais, vejamos-lhes.

O primeiro fator, remete-se a realização efetiva do valor-de-uso, onde, este só, diz Marx, "se realiza com a utilização ou o consumo" (MARX, Karl. 1996, p. 42). Assim, percebe-se que o valor-de-uso só estará presente no objeto quando este tiver uma utilidade ou um uso para a realização de determinando necessidade. E, o segundo fator remete-se ao valor-de-troca, sendo preciso, fazermos uma apreciação maior deste, para não cairmos na tentação de qualifica-lo em frases desconexas de sentido.

Marx expõe que: "os valores-de-uso são, ao mesmo tempo, os veículos materiais do valor-de-troca” (MARX, Karl. 1996, p. 43). Para compreender o valorde-troca Marx usará fórmulas matemáticas (algébricas), com a finalidade de mostrar que algo não possuí um valor-de-troca restrito, mas "valores-de-trocas equivalentes". O valor-de-troca, conceitualmente, é relativo aos objetos que

\footnotetext{
${ }^{3}$ Embora, Marx ofereça, no corpo da obra, $n$ exemplos que clarificam essa ideia, em uma configuração
} 
pretendem-se ser sujeitados ao processo de troca, considerando o aspecto de quantidade, retirando, desta relação de troca, o aspecto de valor-de-uso, assim como posto pelo próprio Marx ao dizer que nas relações de troca "Põem-se de lado os valores-de-uso das mercadorias" (MARX, Karl. 1996, p. 44). Contudo, agora clarificado isso, é importante entender o que resta ao objeto quando seu valor-deuso é deixado em suspensão nesta relação de troca.

Quando se suspende o valor-de-uso, resta, diz Marx, "ainda uma propriedade, a de ser produto do trabalho" (MARX, Karl. 1996, p. 44). Assim, sem a propriedade do uso ou da utilidade, o objeto passa a ser apenas fruto de "tempo de trabalho", esse tempo de trabalho é corporizado no objeto, e, através desta "corporalizarão do trabalho humano" o objetivo passa a possuir um valor. Veremos, neste ponto, o próprio Marx definir sua concepção do sentido de valor.

Inicialmente, acerca da concepção de valor, Marx parece ter a pretensão de iniciar sua análise a partir da "medição de valor" que um objeto pode possuir. Em outras palavras, o esforço de Marx é direcionado na finalidade de mostrar qual o critério deve-se usar para determinar que objeto $x$ tem mais valor que um objeto $y$. A régua de medição postulada por Marx é a quantidade de tempo de trabalho utilizado para a produção do objeto.

Além, disto, Marx apresentou um outro aspecto fundamental para dar-se o valor de algo, acerca deste aspecto Marx chamou-o de "tempo de trabalho socialmente necessário" (MARX, Karl. 1996, p. 46). Desta forma, fica explícito que no processo de troca é levado em conta o tempo de trabalho socialmente necessário, uma vez que, o valor-de-uso fica suspenso, desta forma, sobre a igualdade de valor entre mercadorias. Marx elucida que "Mercadorias que contêm iguais quantidades de trabalho, ou que podem ser produzidas no mesmo tempo de trabalho, possuem, consequentemente, valor da mesma magnitude" (MARX, Karl. 1996, p. 46). Assim, para comparar-se mercadorias, Marx indica que os fatores a serem considerados são o valor da mercadoria ao qual é estabelecido pelo segundo fator, o tempo de trabalho socialmente necessário.

No entanto, essa comparação de valor possuí uma peculiaridade, tendo em vista que, o tempo de trabalho pode variar dependendo da produtividade, o que Marx conceituar como "força produtiva”, onde para Marx (1996, p. 47):

A produtividade do trabalho é determinada pelas mais diversas circunstâncias, entre elas a destreza média dos trabalhadores, o grau de desenvolvimento da ciência e sua aplicação tecnológica, a organização social do processo de produção, o volume e a eficiência dos meios de produção, e as condições naturais.

quase que pedagógica, não é interessante as evidenciar aqui, sendo-as possível de apreciação pelo conhecedor em um momento posterior. (Cf. MARX, Karl, 1996, p. 43). 
Em linhas gerais, acerca desta questão sobre a produtividade e da atribuição de valor, pode-se entender da seguinte forma: quanto maior o tempo de trabalho, como, por exemplo, a lapidação de um fragmento de diamante, maior será o seu valor, e, antagonicamente, quanto menor o tempo de trabalho, com, por exemplo, a produção de garrafas de plástico, menor será seu valor. Portanto, o valor de uma mercadoria estará sempre ligado diretamente ao tempo médio socialmente necessário para a produção da mercadoria.

Para finalizar esse ponto sobre os dois fatores da mercadoria, Marx o-encerra com uma última colocação, diz o Marx: "Uma coisa pode ser valor-de-uso, sem ser valor” (MARX, Karl. 1996, p. 47). Para algo possuir apenas o valor-de-uso, ele, necessariamente, não deve ser fruto de trabalho humano. Isso ocorro quando um produto não é derivado de trabalho, mas possuí utilidade para a realização de determinada necessidade humana, Marx oferece alguns exemplos ilustrativos, expõe Marx: "o ar, a terra virgem, seus pastos naturais, a madeira que cresce espontânea na selva etc.” (MARX, Karl. 1996, p. 47). Esses produtos apontados por Marx, não são frutos do trabalho humano, mas, ainda assim, possuem suas respectivas utilidades de uso, ou seja, são produtos possuidores de valor-de-uso não derivado de trabalho.

\section{O duplo caráter do trabalho materializado na mercadoria}

Marx abre esse ponto retomando a noção de como a mercadoria se apresenta ao sujeito, sendo de duas formas: valor-de-uso e valor-de-troca ${ }^{4}$. Contudo, Marx, de forma gradativa, pretende, neste momento, expor o duplo caráter do trabalho contido na mercadoria. Pode-se entender o duplo aspecto do trabalho em: trabalho concreto e trabalho abstrato - vejamos-lhes a seguir.

I - Todo trabalho é, de um lado, dispêndio de força humana de trabalho, no sentido fisiológico, e nessa qualidade de trabalho igual ou abstrato cria o valor das mercadorias;

II - Todo trabalho, por outro lado, é dispêndio de força humana de trabalho, sob forma especial, para um determinado fim, e, nessa qualidade de trabalho útil e concreto, produz valores-de-uso.

\footnotetext{
${ }^{4}$ Posteriormente, ao tratar sobre a forma simples do valor, em seu conjunto, Marx dirá que a mercadoria só possui valor-de-uso e valor, tendo em vista que o valor-de-troca de uma mercadoria apenas se dar quanto determinada mercadoria entra em relação com outra mercadoria, ou seja, o valor-de-troca ainda não está na mercadoria, o que encontra-se na mercadoria, de forma individual, é, precisamente, valor-de-uso considerando que a mercadoria é produzida para atender determinada necessidade humana, ou seja, ela é útil; e, também, a mercadoria possui valor, assim como veremos a seguir, que a partir do trabalho utilizado para o confeccionar a mercadoria, se atribui valor à mercadoria, haja visto que, trabalho é, de um lado, dispêndio de força humana de trabalho, no sentido fisiológico, e nessa qualidade de trabalho igual ou abstrato cria o valor das mercadorias; portanto, de forma individual a mercadoria só possui valor-de-uso e valor, sendo, o valor-de-troca colocado só na relação de equiparar com o valor de outra mercadoria. (Cf. MARX, Karl. 1966, p. 68-69).
} 
Assim, apreende-se que, em ambos fatores, o trabalho sempre será dispêndio de força humana de trabalho, contudo, suas distinções encontram-se na qualidade do trabalho, onde no trabalho abstrato cria-se o valor das mercadorias, enquanto que no concreto produz-se valores-de-uso. Para clarificar, essa colocação, é interessante apreciar os exemplos didáticos ofertados pelo Marx.

Marx, de forma ilustrativa, usará duas mercadorias - um casaco e 10 metros de linho - para expor essa distinção entre trabalho concreto e trabalho abstrato. $\mathrm{O}$ casaco é produto do trabalho útil e concreto, tendo em vista que, o casaco é valorde-uso, já que, ele possui uma utilidade para determinada necessidade humana. E, o trabalho abstrato é o tipo de trabalho necessário para a sua produção, assim, como diz Marx: "Para produzi-lo, [o casaco] precisa-se de certo tipo de atividade produtiva, determinada por seu fim, modo de operar, objeto sobre que opera, seus meios e seu resultado (MARX, Karl. 1996, p. 48, adaptação nossa). Esse ponto é importante, haja vista que, trata-se de entender que dentro do modo de produção de mercadorias, o trabalho abstrato pode assumir diversos tipos de trabalho. Para o Marx, há um tipo de trabalho para a produção do casaco, assim, como há um tipo de trabalho para a produção do linho - oficio de alfaiate e de tecelão. Marx, assim, classifica os tipos de trabalho em: ordem, gênero, espécie, subespécie e variedade - a divisão social do trabalho.

\section{A forma do valor ou o valor-de-troca}

Neste novo ponto, Marx pretende retornar para a questão do valor, não por ter deixado algo inacabado anteriormente, mas, por precisar mostrar como o valor se manifesta na mercadoria, haja vista que, o valor não é algo palpável, sendo, assim, difícil para o sujeito aprecia-lo, ou, até mesmo, entender de onde ele origina-se.

Marx neste ponto, apresentará quatro formulas, afim de evidenciar a questão sobre a corporizarão do valor na mercadoria. As formulas são: A - A forma simples, singular ou fortuita do valor; B - Forma total ou extensiva do valor; C - Forma geral do valor; e D - Forma dinheiro do valor. As veremos com maiores detalhes a seguir; contudo, é imprescindível entender o motivo de Marx as trazerem neste ponto.

Marx alude que as mercadorias se mostram na forma de valores-de-uso, como já foi visto anteriormente, contudo, as mercadorias só são, efetivamente, mercadorias ao passo que elas possuem dois fatores: valor-de-uso e valor. Assim, para entender esse algo que Marx pretende neste ponto, ele pretende parti "do valor-de-uso ou da relação de troca das mercadorias, para chegar as valor aí escondido" (MARX, Karl. 1996, p. 55). Assim, a pretensão do Marx, é entender a manifestação do valor na mercadoria a partir do processo de troca. Vejamos a seguir como ele pretende fazer isso, a partir das quatro formulas mencionadas anteriormente. 
A) A forma simples, singular ou fortuita do valor; essa forma é expressada da seguinte maneira:

\section{$x$ da mercadoria $A=y$ da mercadoria $B$ ou $x$ da mercadoria $A$ vale $y$ da mercadoria B}

$($ Forma Relativa $) 20$ metros de linho $=($ Forma Equivalente $) 1$ casaco

(Forma Relativa) 20 metros de linho valem (Forma Equivalente) 1 casaco

Para entender essa forma, é preciso entender dois conceitos: a forma relativa (primeiro lado da formula) e a forma equivalente (segundo lado da formula). Vejamos, a seguir, o que Marx expõe ao falar sobre: os dois polos da expressão do valor: a forma relativa do valor e a forma equivalente.

$\mathrm{Na}$ forma simples, dar-se a relação entre duas mercadorias - A e B -, sendo a primeira mercadoria (A) de força ativa, e a segunda (B) passiva. A primeira mercadora (A) possui valor relativo e a segunda (B) possui valor equivalente. Um aspecto sobre ambas formas (relativa e equivalente) está na distinção das mercadorias, pois, não seria preciso colocar uma determinada mercadoria $(C)$ em relação à ela mesma - $(\mathrm{x}$ de $\mathrm{C}=\mathrm{x}$ de $\mathrm{C})-$, como, por exemplo, 10 metros de tecido = 10 metros de tecidos, ou seja, o valor relativo na segunda forma, não muda em relação a primeira, são iguais. Desta forma, a forma simples do valor, exige, obrigatoriamente, que as mercadorias, a serem relacionadas na formula, sejam distintas um da outra.

Para distinguir qual das mercadorias encontra-se na posição de valor relativo, basta atentar-se para sua posição dentro da forma simples, observando qual das mercadorias está oferecendo seu corpo para a determinação da equivalência de valor. Vejamos, agora, de forma suficiente, o que significa a forma relativa do valor.

Para se afirmar que 20 metros de linho é equivalente a 1, 2, 3, 4 ou x casacos, isto é, que dada uma x quantidade de linho vale y quantidades de casacos, é preciso admitir que tanto o linho quanto o casaco são grandezas de valor, ou seja, eles são expressões da mesma coisa, assim, linho = casaco é o fundamento da equação. Contudo, resta saber a razão que leva o valor de determinada quantidade de linho poder ser relacionada ao x quantidade de casaco. Para compreender essa questão, diz Marx: "Quando o casaco, como figura do valor, é equiparado ao linho, iguala-se o trabalho inserido naquele com o contido neste" (MARX, Karl. 1996, p. 58). Ou seja, em primeiro lugar, deve-se entender que, assim como apontado anteriormente, o valor se dar pelo tempo médio socialmente necessário a produção da mercadoria, e, neste sentido, ambas mercadorias (A e B) possuem, em seus processos de produções, embora diferentes, tempo de trabalho socialmente necessário. 
No entanto, como trata-se de mercadorias distintas, é evidente que o tempo de trabalho socialmente necessário será distinto, contudo, para Marx (1996, p. 58):

Sem dúvida, o trabalho concreto do alfaiate, o que faz o casaco, difere do executado pelo tecelão, que faz o linho. Mas, equiparando ao do tecelão, reduz-se o trabalho do alfaiate àquilo que é realmente igual em ambos os trabalhos, sua condição comum de trabalho humano. Por esse meio indireto, diz-se que o trabalho da tecelã, ao tecer valor, não possui nenhuma característica que o diferencie do trabalho do alfaiate, sendo, portanto, trabalho humana abstrato. Só a expressão de equivalência de mercadorias distintas põe à mostra a condição específica do trabalho criador de valor, porque ela realmente reduz à substância comum, a trabalho humano simplesmente, os trabalhos diferentes incorporados em mercadorias diferentes.

Desta forma, a equiparação é possível, mesmo em relações com mercadorias distintas, pois, o que a forma simples leva em conta consiste no valor adquirido a partir do trabalho humano incorporados nas mercadorias. Isso tornar-se mais claro, quando Marx, fala sobre o processo de produção, como, por exemplo, a do casaco, onde teve dispêndio de força de trabalho humano, - lembrando que o trabalho sempre será dispêndio de força humana de trabalho -, a força de trabalho do alfaiate, a qual incorporou no casaco, e, tendo em vista que, para Marx "o trabalho humano cria valor, mas não é valor” (MARX, Karl. 1996, p. 59). Então, pode-se compreender que o casaco, criado a partir do dispêndio de força humana de trabalho é um "depositário de valor", assim como qualquer outra mercadoria produzida a partir do trabalho humano.

Ainda sobre a forma relativa do valor, vejamos agora o que Marx propõe por determinação quantitativa da forma relativa do valor.

Marx abre esse ponto evidenciando que para se expressar o valor de qualquer mercadoria, sempre é preciso que tenha uma determinada quantidade de mercadoria, e, essa determinada quantidade de mercadoria possui x quantidade de trabalho humano. Embora pareça que Marx esteja fazendo uma revisão das ideias já postas, ele está apenas fazendo uma preparação do terreno para pôr uma nova característica importante para a compreensão da forma simples do valor. Vejamos a importância que essa quantidade de mercadoria possui para a determinação quantitativa da forma relativa do valor.

Seguindo a forma simples do valor: 20 metros de linho = 1 casaco, ou 20 metros linho valem 1 casaco, isso quer dizer que, para cada 1 casaco há substância de valor que corresponde a 20 metros de linho. Contudo, Marx propõe que se imagine, um determinando lugar, onde a matéria para a produção do linho esteja escarça, com poucas plantações que fornecem a fibra para produzir o linho, neste caso, o valor do

\footnotetext{
${ }^{5}$ Expressão utilizada por Karl Marx (in.: MARX, Karl. 1996, p. 59).
} 
linho iria aumentar, pois, o tempo de trabalho socialmente necessário iria ser maior. Se neste lugar, o tempo de trabalho socialmente necessário para a produção do linho dobrar, o valor do linho também dobrara, assim, 20 metros de linho $=\mathbf{2}$ casacos, ou 20 metros de linho valem 2 casacos. Neste novo cenário, or casaco equivale apenas a metade do trabalho humano utilizado para produzir 20 metros de linho. Contudo, Marx propõe imaginar um cenário inverso a este, onde o tempo para produzir 20 metros de linhos caiu pela metade, assim, o valor do linho também cairá consequentemente e na mesma medida. Na forma simples do valor: 20 metros de linho $=1 / 2$ de casaco, ou 20 metros de linho valem $1 / 2$ de casaco.

Assim, Marx apresenta essa característica importante para a forma simples do valor, onde o tempo de trabalho socialmente necessário é a chave para se estabelecer o valor das mercadorias, sendo, desta forma, o valor das mercadorias relativo de acordo com o tempo de trabalho humano incorporado na mercadoria.

Tendo deixado isso suficientemente claro - a questão sobre a forma relativa do valor -, vejamos agora, outro ponto importante para a forma simples do valor, a forma de equivalente.

Marx apresenta, uma ilustração, para entendermos a forma de equivalência. Nesta ilustração ele troca a busca pelo valor pela busca do peso. Ele pede para pensarmos em um tijolo, físico e corpóreo, logo, valor-de-uso. O tijolo possui um determinado peso, porém, mesmo sendo ele corpóreo e passível a apreciação física, não é possível que o indivíduo, somente, a partir da apreciação física - visual, palpável, sonoro, e etc. - possa determinar seu peso. Para fazê-lo - determinar o peso do tijolo - o sujeito deverá colocar o tijolo em relação de equivalência com peso de ferro, onde, este tem seu peso determinado. Assim, na formula simples do peso: $\mathrm{x}$ peso de tijolo $=\mathrm{x}$ peso de ferro, ou $\mathrm{x}$ peso de tijolo vale $\mathrm{x}$ peso de ferro.

Assim, para se achar o peso de algo, deverá equiparar este com algo que também tenha peso; logo, o peso deve ser a propriedade comum entre os objetos a serem equiparados. Assim, em paralelo a está conclusão, para se encontrar o valor de algo, deve equiparar este com algo com valor, o que Marx chamará de "elemento social” (Cf. MARX, Karl. 1996, p. 65), o valor que é, neste caso, o elemento comum entre ambas mercadorias.

Assim, para achar o valor do linho utilizara-se o casaco, pois, ambos possuem valor, eles não serão equiparados pelas características físicas de seus corpos, haja vista que, o valor do qual trata-se de encontrar é uma relação social não materializada. Neste ponto, Marx tece uma crítica aos economistas políticos de sua época, onde, ofuscados pela visão burguesa, optaram por buscar o valor das mercadorias através do dinheiro (ouro ou prata), quando a formula simples do valor - x da mercadoria $A$ = y da mercadoria $B$ ou x da mercadoria A vale y da mercadoria $B$ - bastaria para determinar o valor das mercadorias. 
Para concluir o ponto sobre a forma de equivalente, Marx irá retornar ao primeiro pensador que primeiramente analisou a forma do valor - Aristóteles -, com a finalidade de mostrar o motivo que levou Aristóteles a interromper sua análise. Marx mostra que Aristóteles não conseguiu terminar sua análise sobre a forma do valor, pois, ele não possuía as condições de entender o conceito de valor. Aristóteles põe 5 camas em equidade com 1 casa, equivalente também a 5 camas em equidade com determinada quantia de dinheiro. Na forma simples do valor: 5 camas $=1$ casa "equivale também" a 5 camas = tanto de dinheiro. Para entender por que 5 camas podem ser trocadas por uma casa, e, como também é igual a troca entre 5 camas e um tanto de dinheiro, Aristóteles precisaria, necessariamente, entender o conceito de valor, contudo, Marx alude que: "que a sociedade grega repousava sobre a escravatura, tendo, por fundamento, a desigualdade de homens e de suas forças e trabalhos" (MARX, Karl. 1996, p. 68). Assim, as condições do tempo histórico de Aristóteles não poderiam conduzi-lhe a determinação do conceito de valor, pois, é somente quando se possui a ideia de igualdade entre homens, que se pode expressar o valor, ou seja, através da equiparação da força de trabalho humano contida nos corpos das mercadorias.

Para encerramos nossa questão sobre a forma simples, singular ou fortuita do valor, veremos agora, o último ponto que se refere a forma simples do valor, em seu conjunto. Marx abre esse ponto fazendo uma retomada ao que foi dito no início do primeiro capítulo, ao dizer que: "mercadoria é valor-de-uso e valor-de-troca". Marx percebe que a mercadoria não pode ser isso, se o considerado for a mercadoria individual. A mercadoria é, portanto, valor-de-uso ou útil e valor, pois, a mercadoria materializada e de forma individual não manifesta o valor-de-troca, sendo este, dependente da equivalência de valor entre essa e outra mercadoria. Assim, a mercadoria materializada possui utilidade para determinada necessidade humana, e valor, pois, a mercadoria é fruto de dispêndio de força humana de trabalho, no sentido fisiológico, e nessa qualidade de trabalho igual ou abstrato cria o valor das mercadorias.

A) A forma total ou extensiva do valor; essa forma é expressada da seguinte maneira:

\section{$\mathrm{z}$ da mercadoria $\mathrm{A}=u$ da mercadoria $\mathrm{B}, \mathrm{ou}=\boldsymbol{v}$ da mercadoria $\mathrm{C}, \mathrm{ou}=\boldsymbol{w}$ da mercadoria $D$, ou $x$ da mercadoria $E$, ou = etc.}

20 metros de linho $=1$ casaco, ou $=10$ quilos de chá, ou = 40 quilos de café, ou $=1$ quarter de trigo, ou $=\mathbf{2}$ onças de ouro, ou = $1 / 2$ tonelada de ferro, ou $=$ etc .

(Primeiro lado $)$ forma total $=($ Segundo lado $)$ forma extensiva do valor

\footnotetext{
${ }^{6}$ Essa conceituação é colocada por Marx na primeira sessão titulada "Os dois fatores da mercadoria: valor-de-uso e valor: (substância e quantidade de valor)”. (Cf. MARX, Karl. 1996, p. 41-43).
} 
Para apresentar o entendimento desta segunda forma, Marx parti da forma extensiva do valor relativo (segundo lado). Nesta forma, Marx pretende mostrar que determinada mercadoria pode ser equipara com mercadorias distintas, pois, agora, o trabalho que cria se apresenta igual a qualquer outro. Assim, em linhas geral, o segundo lado da forma, ao passa que, pode adquirir qualquer corpo de mercadoria, para equipar-se ao primeiro lado da forma, acaba por deixar evidente que o valor de $z$ da mercadoria A vale o valor de $u$ da mercadoria $B$, ou de $v$ da mercadoria $C$, ou de $w$ da mercadoria $\mathrm{D}$, ou de $x$ da mercadoria $\mathrm{E}$, ou etc., neste sentido, qualquer mercadoria pode se equipar a qualquer mercadoria, por que o trabalho de produção das mercadorias, neste caso, são equivalentes.

B) Forma geral do valor; essa forma é expressada da seguinte maneira:

1 casaco

10 quilos de chá

40 quilos de café

1 quarter de trigo

20 metros de linho

2 onças de ouro

$1 / 2$ tonelada de ferro

$x$ de mercadoria A

etc. mercadoria

Para entender a forma geral do valor relativo, é preciso entender que nesta forma, há uma eleição de uma determinada mercadoria do mundo das mercadorias, para empregar o papel de equivalente geral das demais mercadorias. Desta forma, Marx dirá que:

A forma geral do valor, que torna os produtos do trabalho mera massa de trabalho humano sem diferenciações, mostra através de sua própria estrutura, que é na expressão social do mundo das mercadorias. Desse modo, evidencia que o caráter social específico desse mundo é constituído pelo caráter humano geral do trabalho. (KARL, Marx. 1996, p. 76).

Ou seja, o trabalho têxtil na produção do linho - quantidade de dispêndio de força humana de trabalho, no sentido fisiológico - será reduzido como o fator para equiparar o valor das demais mercadorias, lembrando que a qualidade de trabalho igual ou abstrato cria o valor das mercadorias, e, assim, através do valor do linho se medirá o valor das demais mercadorias.

Assim, ao passo que uma mercadoria se distingue do mundo das mercadorias, e se torna equivalente universal do valor, para Marx, este "funciona como dinheiro" 
(KARL, Marx. 1996, p. 76). Contudo, para Marx, a mercadoria (B) - o equivalente universal, que funciona como dinheiro - com maior destaque entre o mundo das mercadorias, é o ouro, onde este assume o papel de dinheiro, assim como veremos a seguir, onde Marx utiliza a forma geral do valor, trocando o linho - mercadoria B pelo ouro como expressão de dinheiro.

A) Forma dinheiro do valor. Essa forma é expressada da seguinte maneira:

20 metros de linho

1 casaco

10 quilos de chá

40 quilos de café

1 quarter de trigo

2 onças de ouro

2 onças de ouro

$1 / 2$ tonelada de ferro

$\mathrm{x}$ de mercadoria $\mathrm{A}$

Para Marx, há diferenças entre a forma simples para a forma total ou extensiva do valor, e da forma total ou extensiva do valor para a forma geral do valor, contudo, entre a forma geral do valor para a forma dinheiro do valor, a diferença consiste apenas na substituição do linho pelo ouro como equivalente geral.

Para Marx (1996, p. 76):

O ouro se confronta com outras mercadorias, exercendo a função de dinheiro, apenas por se ter, antes, a elas, anteposto na condição de mercadoria. Igual a outras mercadorias, funcionou também como equivalente singular em operações isoladas de troca, ou equivalente particular junto a outros equivalentes.

A utilização do ouro como equivalente geral, passo a passo, segundo Marx, o tornou em "mercadoria-dinheiro", assim, a forma geral do valor - forma $\mathrm{C}$-, tornouse a forma dinheiro do valor - forma D -, ou seja, forma preço. Marx, assim, para chegar ao entendimento da forma dinheiro valor, desenvolve de forma linear as demais formas - A, B, e C - para chegar até a forma dinheiro do valor, desta forma, pode-se dizer que o ponto de partida, a forma simples do valor, é o precedente chave, o germe, nas palavras de Marx, para se chegar a forma dinheiro.

\section{O fetichismo da mercadoria: seu segredo}

Neste ponto, Marx pretende mostrar o segredo da mercadoria, algo que não é perceptível na mercadoria concreta, pois, ao observar a mercadoria, à primeira vista, não se nota nada de estranho. Sabe-se que ali é um produto que possui um valor-de- 
uso, tendo em vista que toda mercadoria é útil a uma determinada necessidade humana. Assim, o caráter misterioso que Marx quer apresentar, não advém do valorde-uso da mercadoria, nem do próprio valor da mercadoria, pois, assim como visto antes, o valor é derivado do dispêndio de força humana de trabalho, no sentido fisiológico; e ao observar a mercadoria, é possível determinar a quantidade de dispêndio de força humana utilizado na produção da mercadoria. Então, onde, no produto de trabalho ao assumir a forma de mercadoria, há algo de misterioso?

Para Marx o segredo da mercadoria, está na forma da mercadoria, pois, diz Marx: "A igualdade dos produtos do trabalho fica disfarçada sob a forma de igualdade dos produtos do trabalho como valores" (KARL, Marx. 1996, p. 8o). Desta forma, a forma mercadoria é misteriosa - possui algo de secreto - por ocultar as características sociais do trabalho dos homens, naturalizando isso, como propriedade social inerente da própria mercadoria. Para Marx, existe uma espécie de fetichismo do mundo das mercadorias, ao qual, diz Marx "decorre conforme demostra a análise precedente, do caráter social próprio do trabalho que produz mercadorias" (KARL, Marx. 1996, p. 81). Assim, a seguir, tentaremos compreender o que Marx está a querer dizer por "caráter social próprio do trabalho", e a razão deste se ocultar na forma mercadoria.

Marx alude que as relações sociais não se apresentam entre o indivíduo e seu trabalho, mas, somente, como relações materiais entre pessoas e relações sociais entre coisas. É, somente, no processo de troca que os produtos de trabalham se apresentam como valores, ou seja, uma realidade socialmente homogênea, distinta de sua realidade enquanto objeto útil, perceptível pelos sentidos. Assim, o produto de trabalho possui dois fatores sociais, sendo estes, o fator de utilidade à determinada necessidade humana, e o fator de útil as multiplicas necessidades dos próprios produtores, ao passo que, uma espécie de trabalho pode ser trocada por qualquer outra espécie de trabalho com que se possa equiparar-se.

Para Marx, os indivíduos não estabelecem relações com suas mercadorias enquanto valores, por vê-las apenas como manifestação material de trabalho humano. O valor das mercadorias não está escrito diretamente no corpo das mercadorias, ele é escrito, segundo Marx, em "hieróglifo social", ou seja, os produtores precisam traduzir o valor de suas próprias criações. Assim, no processo de troca de mercadorias, os homens estão apenas tentando descobrir o quanto de outras mercadorias equivale a sua própria produção.

Marx, um pouco a frente, trará a história de Robinson, que após um naufrágio, passou a viver numa ilha, isoladamente, e, assim, todos os produtos de seu trabalho são seus, como valor-de-uso, e não valor. Contudo, ao voltar-se para a realidade de produção capitalista, o individualismo não é possível, pois, o homem não está só, ele não é independente, e sim, dependente, já que, as relações de dependência 
constituem o fundamento social. Os produtos de trabalhos, no contexto social, assumem, segundo Marx, a feição fantasmagórica.

Marx faz uma espécie de retrato de sociedade, assim, com Platão faz na República; ele pede para supor:

uma sociedade de homens livres, que trabalham com meios de produção comuns, e empregam suas múltiplas forças individuais de trabalho, conscientemente, como força de trabalho social. Reproduzem-se aqui todas as características do trabalho de Robinson, com uma diferença: passam a ser sociais, ao invés de individuais. Todos os produtos de Robinson procediam de seu trabalho pessoal, exclusivo e, por isso, eram para ele, objetos diretamente úteis. Em nossa associação, o produto total é um produto social. Uma parte desse produto é utilizado como novo meio de produção. Continua sendo social. A outra parte é consumida pelos membros da comunidade. Tem, portanto, de ser distribuída entre eles. O modo dessa distribuição variará com a organização produtiva da sociedade e com o correspondente nível de desenvolvimento histórico dos produtores. Somente para fazer um paralelo com a produção de mercadorias, pressupomos que a participação de cada produtor nos bens de consumo se determina pelo tempo de trabalho. O tempo de trabalho desempenharia, portanto, duplo papel. Sua distribuição socialmente planejada regula a proporção correta das diversas funções do trabalho para as diversas necessidades. Além disso, o tempo de trabalho serve para medir a participação individual dos produtores no trabalho comunitário e sua cota pessoal na parte do produto global destinada ao consumo. Neste caso, as relações sociais dos indivíduos no tocante a seus trabalhos e aos produtos de seus trabalham continuam meridianamente claros, tanto na produção quanto na distribuição. (MARX, 1996, p. 87-88).

Marx, aparentemente, utiliza-se desta ilustração de sociedade de homens livres, para desenvolver uma crítica ao modo de sociedade produtora de mercadorias. Para Marx, neste modelo de sociedade de homens livres, a relação social da mercadoria não se oculta do indivíduo, pois, este sabe de qual tipo de trabalho provem a mercadoria, e, a mercadoria, neste modelo, não é distinguida sobre o caráter de valor-de-troca, tendo em vista que, a mercadoria tem esse duplo aspecto, o primeiro em ser matéria de reposição para a produção, e, o segundo fator, de ser distribuído para o consumo dos componente desta sociedade. Contudo, ao observar a sociedade capitalista de produção de mercadoria - modelo burguês da Europa -, percebe-se que a mercadoria está visível ao homem sobre o signo de valor, a partir do momento de que ela possa ser valor-de-troca. Para Marx, essa estrutura vital da sociedade burguesa, só, diz Marx: "pode desprender-se do seu véu nebuloso e místico, no dia em que for obra de homens livremente associados, submetida a seu controle consciente e planejado" (MARX, Karl. 1996, p. 88). Ou seja, para a superação do modelo, que tem como fundamento as relações diretas de domínio e 
escravidão - sociedade capitalista de produção -, só seria possível, ao passo que os indivíduos, desta sociedade, se tornassem homens livres e conscientes do trabalho empenhado no processo de produção de seus produtos.

Para encerramos, de forma suficientemente clara, a questão sobre o fetichismo da mercadoria, é interessante mostrar um pensamento de Marx, onde ele expõe o que diria a mercadoria dentro do sistema de produção capitalista, se esta pudesse falar, coloca Marx: “Nosso valor-de-uso pode interessar aos homens. Não é nosso atributo material. O que nos pertence como nosso atributo material, é nosso valor. Isto é o que demostra nosso intercâmbio como coisas mercantis. Só como valoresde-troca estabelecemos relações umas com as outras" (MARX, Karl. 1996, p. 92, grifo do autor). Assim, Marx está, através desta ilustração, do pensamento das mercadorias, afirmando que a mercadoria tem valor-de-uso na relação entre a mercadoria e a pessoa, enquanto que, o valor só se realizar na relação de troca, ou seja, quando a meteria possui valor cambiável, derivado através do processo social.

\section{Considerações finais}

Marx teve o devido cuidado em começar O Capital pela questão acerca da Mercadoria. Ao fazermos nossa apreciação analítica e hermenêutica do primeiro capítulo, percebemos uma lógica argumentativa linear, e, se esta característica se estender de forma ampliada, ao todo da obra, pode-se dizer que a questão da Mercadoria será a questão primordial que desenvolvera as demais questões tratadas pelo Marx. Entendemos que sem a colocação sobre os tipos de valor (valor-de-uso; valor-de-troca; e valor) não seria possível, para Marx, desenvolver o segundo capítulo, ao tratar sobre o processo de troca, ou, até mesmo, o terceiro capítulo, ao tratar-se do dinheiro ou a circulação das mercadorias, e, assim, consequentemente, pois, é extremamente perceptível a lógica argumentativa linear utilizada por Marx.

Ao fim desta apreciação acerca da Mercadoria, concluímos que Marx, é felizardo, ao perceber e colocar em questão as quatros formas do valor da mercadoria - I) a forma simples, singular ou fortuita do valor; II) forma total ou extensiva do valor; III) forma geral do valor; e a IV) forma dinheiro do valor. Diferente de Aristóteles, que por razões provenientes das condições de seu tempo histórico, Marx, a partir da análise do contexto de produção capitalista, conseguiu determinar o determinante do valor corporificado da mercadoria, através do dispêndio de força humana de trabalho e do tempo de trabalho socialmente necessário, sendo estes dois fatores a chave que permitem ao homem encontrar e/ou determinar o valor da mercadoria, levando esta, à possuir o valor-de-troca, levando em conta, a necessidade cambiável do sistema capitalista, contrário ao que Marx coloca como sociedade de homens livres e conscientes.

Ainda sobre o valor-de-troca, concluímos que este não está na mercadoria quando esta é vista individualmente. Essa conclusão chega-se ao perceber que 
quando Marx trata da forma simples do valor, em seu conjunto, ele aponta que a Mercadoria só possui valor-de-uso e valor, tendo em vista que, o valor-de-troca de uma mercadoria apenas se dar quanto determinada mercadoria entra em relação com outra mercadoria, ou seja, o valor-de-troca ainda não está na mercadoria; o que encontra-se na mercadoria, de forma individual, é, precisamente, valor-de-uso considerando que a mercadoria é produzida para atender determinada necessidade humana, ou seja, ela é útil; e, também, a mercadoria possui valor, derivada a partir do trabalho utilizado para o confeccionar a mercadoria, haja visto que, trabalho é, de um lado, dispêndio de força humana de trabalho, no sentido fisiológico, e nessa qualidade de trabalho igual ou abstrato cria o valor das mercadorias; portanto, de forma individual a mercadoria só possui valor-de-uso e valor, sendo, o valor-detroca colocado apenas na relação de equiparar-se com o valor de outra mercadoria, tendo em vista a necessidade cambiável do sistema capitalista.

\section{Referências}

MARX, K. O capital: crítica da economia política: livro primeiro. Trad. Reginaldo Sant'Ana. 15. ed. Rio de Janeiro: Bertrand Brasil, 1996.

Submissão: 07. 03. 2019/ Aceite: 15. 07. 2019 